\title{
HTR-Based Power Plants' Performance Analysis Applied on Conventional Combined Cycles
}

\author{
José Carbia Carril, Álvaro Baaliña Insua, \\ Javier Romero Gómez, and Manuel Romero Gómez \\ Department of Energy and Marine Propulsion, ETSNM, University of A Coruña, Paseo de Ronda 51, A Coruña 15011, Spain \\ Correspondence should be addressed to Manuel Romero Gómez; m.romero.gomez@udc.es
}

Received 28 October 2014; Revised 16 February 2015; Accepted 16 February 2015

Academic Editor: Borut Mavko

Copyright ( 2015 José Carbia Carril et al. This is an open access article distributed under the Creative Commons Attribution License, which permits unrestricted use, distribution, and reproduction in any medium, provided the original work is properly cited.

In high temperature reactors including gas cooled fast reactors and gas turbine modular helium reactors (GT-MHR) specifically designed to operate as power plant heat sources, efficiency enhancement at effective cost under safe conditions can be achieved. Mentioned improvements concern the implementation of two cycle structures: (a), a stand alone Brayton operating with helium and a stand alone Rankine cycle (RC) with regeneration, operating with carbon dioxide at ultrasupercritical pressure as working fluid (WF), where condensation is carried out at quasicritical conditions, and (b), a combined cycle (CC), in which the topping closed Brayton cycle (CBC) operates with helium as WF, while the bottoming RC is operated with one of the following WFs: carbon dioxide, xenon, ethane, ammonia, or water. In both cases, an intermediate heat exchanger (IHE) is proposed to provide thermal energy to the closed Brayton or to the Rankine cycles. The results of the case study show that the thermal efficiency, through the use of a CC, is slightly improved (from $45.79 \%$ for BC and from $50.17 \%$ for RC to 53.63 for the proposed CC with $\mathrm{He}_{-} \mathrm{H}_{2} \mathrm{O}$ operating under safety standards).

\section{Introduction}

The main stimulus for applying nuclear energy to large thermal energy conversion plants is a result of the evermore increasing costs of fossil fuels along with the very restrictive emissions regulations. Indeed, the urgent need to find a viable and cost effective alternative power resource is accentuated by the barriers imposed by global warming potential (GWP) and zero ozone depletion potential (ODP) regulations with particular interest in greenhouse emissions, nitrogen oxides, sulfur oxides, and particulate matters. As a consequence, the viable road map/course choosing a safe and cost effective technology for the forthcoming decades may require the application of the IV generation of nuclear fission technology [1]. Some improvements aimed at thermal efficiency enhancement can be implemented on IV generation reactors. Mentioned improvements concern the implementation of two cycle structures: (a), a Rankine cycle (RC) with regeneration operated with carbon dioxide at ultrasupercritical pressure as the working fluid (WF), where condensation is carried out at quasicritical conditions, and (b), a combined cycle (CC), in which the topping closed Brayton cycle (CBC) operates with helium as the WF, while the bottoming RC is alternatively operated with carbon dioxide, xenon, ethane, water, or ammonia at ultrasupercritical pressure and quasicritical conditions.

The Status of High Temperature Gas Cooled Reactors. High temperature reactors (HTRs), commonly a graphitemoderated, and helium-cooled thermal reactor as well as multiple reheat helium Brayton cycles for sodium cooled fast reactors $[2,3]$ operate at a high outlet gas temperature $(1123 \mathrm{~K})$. HTRs have various possibilities as high temperature heat sources besides electric power generation. Also, HTRs are characterised by their high level of safety due to the large negative temperature coefficient of fuel and large heat capacity of graphite as well as high structural stability of graphite under high temperature conditions.

In the case of HTRs, the core consists of graphite blocks including fuel pellets of coated fuel particles dispersed in 
graphite. The core is cooled by helium gas at an outlet temperature approaching $1270 \mathrm{~K}$. HTRs are able to achieve high burn-up in spite of the low power density. The high burnup is brought about with hard neutron spectrum and high conversion ratio due to high temperature, low absorption of neutron in graphite moderator, and low parasitic absorption of neutron owing to the minimal use of metallic materials.

The gas-cooled fast reactor (GFR) system features a fastneutron spectrum and closed fuel cycle for efficient conversion of fertile uranium and management of actinides [4]. The reactor is helium cooled, with an outlet temperature of $1123 \mathrm{~K}$ and using a direct $\mathrm{BC}$ gas turbine for high thermal efficiency. Several fuel forms are being considered for their potential to operate at very high temperatures and to ensure an excellent retention of fission products: composite ceramic fuel, advanced fuel particles, or ceramic clad elements of actinide compounds. Core configurations are being considered based on pin-or plate-based fuel assemblies or prismatic blocks.

Safety, efficiency and cost effectiveness have been the focal issues of researchers over the last two decades on HTR technologies. Since efficiency depends strongly on the reactor outlet temperature, research effort has been made on increasing the operating temperature of HTRs. Among the most relevant achievements in the field are describing a preliminary study on nuclear characteristics of plutonium burning with a high temperature gas-cooled reactor (HTR), demonstrating that an HTR has good potential for plutonium utilization, with core property changes at around the same quantity of plutonium as fissile uranium [5]. In [3] the high temperature gas-cooled reactor development in China is briefly described. The References [6,7] show that Modular High Temperature Reactor (Modular HTR) is one of the most effective solutions to the problem of unstable supply of the fossil resources and the aggravation of the global environment. The authors of [8] are working on a program consisting in the design of a helium based gas cooled GTMHR plant and R\&D on a closed-cycle helium gas turbine system for the existing GT-MHR designed to operate with an outlet coolant temperature of $1123 \mathrm{~K}$. In [9] a time-dependent reliability evaluation of a two-loop passive decay heat removal (DHR) system was performed as part of the interactive design process for a helium-cooled fast reactor. The authors discovered that the smaller pressure loss through the DHR heat exchanger than through the core would make the flow to bypass the core through one DHR loop, if two loops operated in parallel. El-Genk and Tournier [10] examine the effects of using noble gases and binary mixtures as reactor coolants and direct CBC WFs on the performance of terrestrial nuclear power plants and the size of the turbomachines. Results show that for the same reactor exit temperature and pressure losses in piping and heat exchange components; the higher pressure losses in the nuclear reactor decrease the net peak efficiency of the plant with $\mathrm{He}-\mathrm{Xe} \mathrm{WF}(15 \mathrm{~g} / \mathrm{mole})$ by a little more than $2 \%$ points, at a higher cycle compression ratio than with $\mathrm{He}$ WF.

In [11] helium Brayton cycles with multiple reheat and intercooling states are presented for SFRs with reactor outlet temperatures in the range of $510-650^{\circ} \mathrm{C}$. The study indicates that the multiple reheat helium cycle is the preferred choice over the $\mathrm{SCO}_{2}$ cycle for sodium cooled fast reactors. In [12]

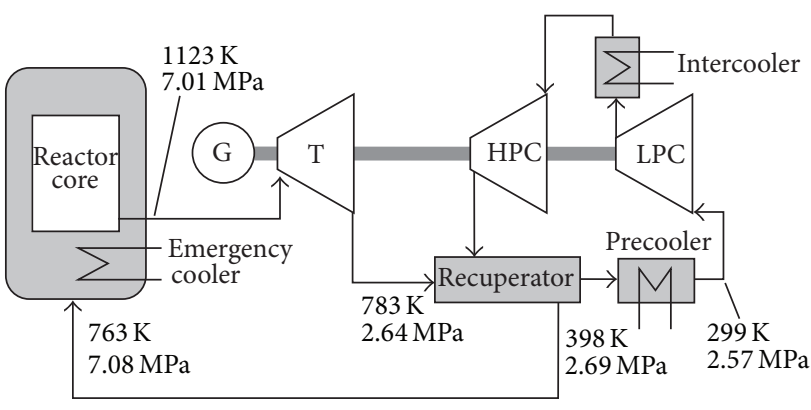

FIgURE 1: Flow diagram of the GT-MHR [14].

TABLE 1: Main technical specifications of the GT-MHR [14].

\begin{tabular}{lc}
\hline Full thermal reactor power & $600 \mathrm{MW}$ \\
Electricity generation efficiency & $48.00 \%$ \\
Helium coolant temperature (inlet/outlet) & $763 / 1123 \mathrm{~K}$ \\
Helium pressure & $7.15 \mathrm{MPa}$ \\
Electricity production efficiency (net) & $46.29 \%$ \\
Helium pressure at PCS inlet & $7.07 \mathrm{MPa}$ \\
Helium pressure at PCS outlet & $7.16 \mathrm{MPa}$ \\
Helium flow rate through the turbine & $316.96 \mathrm{~kg} / \mathrm{s}$ \\
\hline
\end{tabular}

the hydrodynamics of helium and fuel particles have been simulated in a conceptual helium-cooled spout fluidized bed nuclear reactor. The results of the numerical simulations showed that the unique mixing ability of the spout fluidized bed nuclear reactor gives rise to uniform particle distributions and this uniformity enhances the heat transfer and hence the power produced by the reactor. Epiney et al. [13] investigate the natural convection capability of the dedicated DHR loops for the Generation IV gas (helium-) cooled fast reactor under depressurized conditions, while injecting a heavy gas into the system. It has been shown that, among the gases investigated, $\mathrm{CO}_{2}$ is the best choice from the thermalhydraulics viewpoint, being able to cool the core satisfactorily for a broad range of injection rates.

High Temperature Reactors Based Power Plants Technology. A novel type of nuclear power plant for thermal to electric energy conversion has been recently proposed, known as the gas turbine modular helium reactor (GT-MHR). In this type of reactor, the heat of reaction is transferred to a WF (helium) which drives a gas turbine coupled to an electric alternator. The thermal $\mathrm{BC}$ with regeneration is being considered for this application. Because of the balance of the reaction, this type of reactor is fail-safe because if left uncontrolled it will "wind down" to an idle mode.

The conceptual scheme of a large GT-MHR power plant exhibits the configuration shown in Figure 1 [14]. Main technical specifications of the GT-MHR are described in Table 1 . In the primary system illustrated by the flow diagram of Figure 1, the core heated helium flows through the hot duct to turbine inlet. Following the expansion in the turbine, the helium flows through the recuperator low-pressure side, releasing heat to the helium of the recuperator high-pressure 
TABLE 2: Major design parameters of the GT-MHR [8].

\begin{tabular}{lc}
\hline Full thermal reactor power & $600 \mathrm{MW}$ \\
Helium coolant temperature (inlet/outlet) & $867 / 1223 \mathrm{~K}$ \\
Helium pressure at PCS inlet & $2.55 \mathrm{MPa}$ \\
Helium pressure at PCS outlet & $5.10 \mathrm{MPa}$ \\
Helium flow rate through the turbine & $324 \mathrm{~kg} / \mathrm{s}$ \\
\hline
\end{tabular}

TABle 3: Nuclear power plant with direct CBC, helium WF, and single-shaft turbo-machine [10].

\begin{tabular}{lc}
\hline Full thermal reactor power & $600 \mathrm{MW}$ \\
Helium coolant temperature (inlet/outlet) & $889 / 1179 \mathrm{~K}$ \\
Turbine input temperature & $1173 \mathrm{~K}$ \\
Turbine input pressure & $6.70 \mathrm{MPa}$ \\
Turbine output temperature & $914 \mathrm{~K}$ \\
Turbine output pressure & $3.44 \mathrm{MPa}$ \\
Helium pressure at PCS inlet & $2.55 \mathrm{MPa}$ \\
Helium pressure at PCS outlet & $5.10 \mathrm{MPa}$ \\
Helium flow rate through the turbine & $324 \mathrm{~kg} / \mathrm{s}$ \\
\hline
\end{tabular}

side according to the counter-current flow scheme. Then helium is cooled in the precooler. Subsequently, the helium flows through high and low pressure compressors with intermediate cooling in the intercooler. After the high pressure compressor, the helium flows through the recuperator high pressure side where it is heated through heat exchange with helium flowing out of the turbine [15]. Heated helium results from reactor inlet through the coaxial gap between the GTMHR cross vessel and the hot duct [14]. Helium circulation in the primary circuit is performed by compressors operating during

(i) plant power operation, due to helium expansion in the turbine,

(ii) modes of start-up, shutdown and cooling down through PCS (when turbine power is insufficient) or due to generator motor mode operation from the external electric network.

One of the ways to increase the efficiency of a combined $\mathrm{CC}$ consists of increasing the reactor output temperature. In this way, another interesting architecture is presented where the output/input temperatures of the reactor are increased, approaching values of $1223 / 867 \mathrm{~K}$. The main parameters are depicted in Table 2.

The plant layouts in Table 3 with single-shaft turbo machines have relatively low thermal efficiencies, but offer the simplest configurations, the highest reliability and the lowest capital cost. A CBC with a single-shaft turbomachine is easy to control during start-up and planned shutdown. In addition, the regulation of the electrical power during rapid changes in the load demand, and the protection of the turbo-machine against speed-up (in case of a loss of load) are achieved effectively, using a bypass valve between the inlet of the compressor and the outlet of the turbine, in conjunction with changing the helium inventory in the loop.
The carried out design study aims to develop higher efficient CC architectures without significant modifications of the basic proven technologies.

\section{Proposed GT-MHR Power Plant Architectures}

In this study, two structural plant options are proposed to increment the thermal efficiency of the power plant powered by GT-MHRs.

These optional plant structures consist of

(i) A RC depicted with Figure 2(a) with carbon dioxide as the WF condensed at quasicritical conditions connected to the HTR by means of a heat recovery exchanger HRE.

(ii) A CC depicted by Figure 2(b) where a CBC operates with helium and the bottoming RC optionally operates with carbon dioxide, xenon, ethane, ammonia and water. Xenon, carbon dioxide and ethane are condensed at quasicritical conditions, while ammonia or water is condensed at ambient temperature associated to its corresponding pressure.

The basic structure of the RC powered by a GT-MHR is shown in Figure 2(a). Since the pressure of the reactor coolant does not match the pressure of the RC, a heat recovery exchanger must be installed between the reactor and the RC devices. With regard to the CC shown in Figure 2(b), the gas turbine and compressor are connected to the HTR by means of an intermediate heat exchanger. On the whole, the basic structure of the proposed CC is similar to that of conventional fossil fuel based CC power plants with the only difference being the power source, which in this case is a GT-MHR cooled by helium.

The net energy flow supplied by the reactor is described by the first principle (mass and heat balances). Assuming that the CC power plant is affected by inherent heat losses including irreversibilities, the useful heat flow supplied by the HTR to the plant can be estimated as

$$
\mathrm{Q}_{\mathrm{HTR}}=\dot{m} \cdot C_{p} \cdot\left(T_{o}-T_{i}\right)=\dot{m} \cdot\left(h_{o}-h_{i}\right) .
$$

The schemes of both architectures are shown in Figures 3 and 4. The RC shown in Figure 3 takes the thermal energy from a HTR via a heat recovery exchanger. High and low pressure turbines with an intermediate reheater are installed. The condensation phase is carried out under quasicritical conditions ( $295 \mathrm{~K}$ and 59.82 bar) for which the heat flow rate to the heat sink will be the lowest possible. A regenerator captures the heat of the WF at the low pressure turbine exhaust which is recuperated, thereby contributing to efficiency enhancement.

The CC shown in Figure 4 takes the thermal energy from an HTR via a heat exchanger. The $\mathrm{CBC}$ operates with helium with a pressure ratio such that $\left(2.27<p_{\text {rat }}<7.72\right)$. The rejected heat at a heat recovery exchanger is used by the bottoming RC which operates with carbon dioxide, xenon, ethane, ammonia, or water (in this case, carbon dioxide). Two high and low pressure turbines with an intermediate reheater are installed. The condensation phase is carried out under 


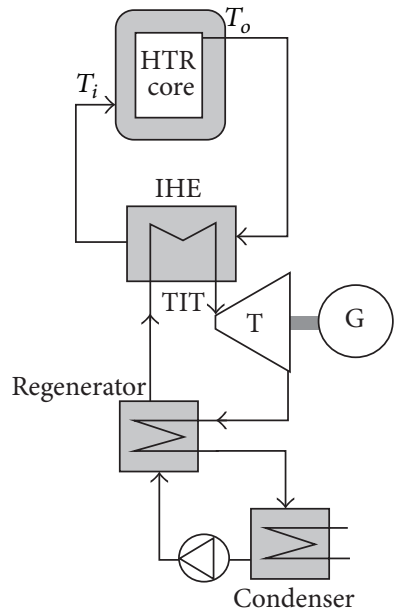

(a)

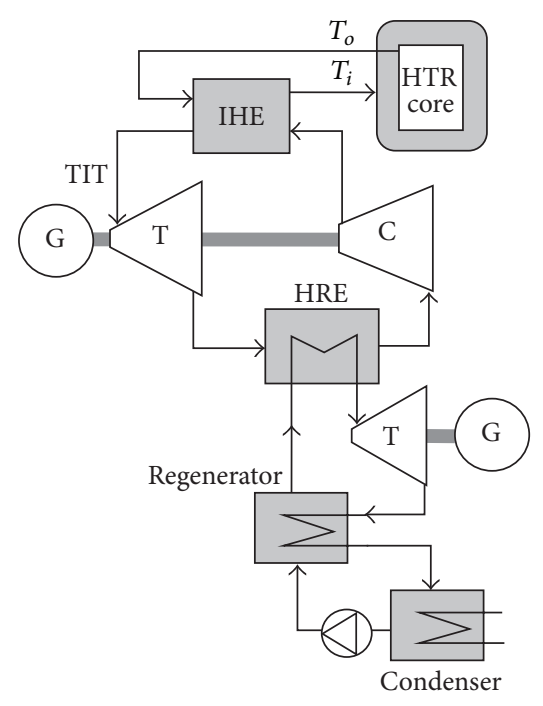

(b)

Figure 2: Flow diagrams of the proposed GT-MHR cycles' structure based on helium cooled gas reactor [14].

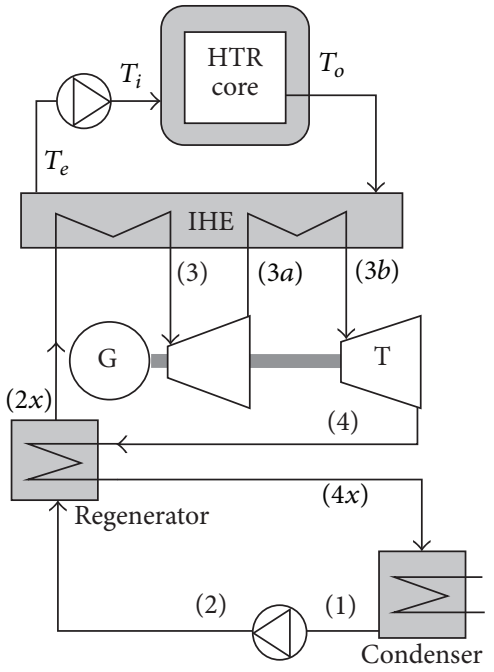

$$
\begin{aligned}
& T_{i}=867 \mathrm{~K} \\
& T_{o}=1223 \mathrm{~K} \\
& T_{e}=848 \mathrm{~K} \\
& p(\mathrm{HTR})=70 \mathrm{bar} \\
& \mathrm{TIT}=1143 \mathrm{~K} \\
& T(1)=295 \mathrm{~K} \\
& T(2)=334.6 \mathrm{~K} \\
& p(2)=400 \mathrm{bar} \\
& T(2 x)=774.2 \mathrm{~K} \\
& T(3)=1143 \mathrm{~K} \\
& p(3)=384.16 \mathrm{bar} \\
& T(3 b)=1143 \mathrm{~K} \\
& T(4)=967.8 \mathrm{~K} \\
& p(4)=59.82 \mathrm{bar} \\
& T(4 x)=354.6 \mathrm{~K}
\end{aligned}
$$

FIgURE 3: Diagram of the RC-based power plant operating with carbon dioxide, powered by a helium-cooled HTR.

quasicritical conditions ( $295 \mathrm{~K}$ and 59.82 bar) for which the heat flow rate to the heat sink will be the lowest possible. A regenerator captures the heat of the WF at low pressure turbine exhaust which is recuperated, hence contributing to efficiency enhancement.

\section{Cycle Efficiency}

The main condition to implement a viable combined cycle (CBC-RC) based on the existing state of the art technology with regard to high temperature gas-cooled reactors requires the increase of gas turbine exhaust gas temperature. To do so, it is necessary to increase the pressure of the cooling gas in the reactor core, as well as to suppress the regeneration phase, being substituted by the heat recovery exchanger to transfer the thermal energy to the RC.

The only technically achievable way of improving cycle efficiency is by pushing the upper temperature higher. In the existing state of available technology, fluid temperature is limited by the materials available that can withstand elevated temperatures while maintaining their mechanical properties.

With regard to the RC, there are at least four processes, each changing the state of the WF. These states are identified by numbers in the diagram shown in Figure 4 where the plant structure as well as the T-s diagrams associated with the physical components (CBC and $\mathrm{RC}$ ) is depicted. Thermal efficiency is bounded due to the irreversibility associated with the fulfilment of the second law of thermodynamics, which is computed according to the following.

Mass and energy balance in all processes:

$$
\begin{gathered}
\sum \dot{m}_{\text {in }}=\sum \dot{m}_{\text {out }}, \\
0=\dot{Q}-\dot{W}+\sum \dot{m}_{\text {in }} h_{\text {in }}-\sum \dot{m}_{\text {out }} h_{\text {out }} .
\end{gathered}
$$

The thermal efficiency of the RC is defined by

$$
\eta_{\mathrm{RC}}=\frac{q_{i \mathrm{RC}}-q_{o \mathrm{RC}}}{q_{i \mathrm{RC}}}
$$

With regard to the $\mathrm{CBC}$, the $T$-s diagram is shown in Figure 4(b). The thermal efficiency defined as the ratio of the network to the total input heat flow rates is expressed as

$$
\eta_{\mathrm{BC}}=\frac{q_{i \mathrm{BC}}-q_{\mathrm{oBC}}}{q_{i \mathrm{BC}}}
$$

The thermal efficiency of a $\mathrm{BC}$ depends on the pressure ratio, the specific heat ratio of the WF, the top and bottom cycle temperatures, the isentropic efficiency of compressors and turbines and the inherent irreversibilities, which for 


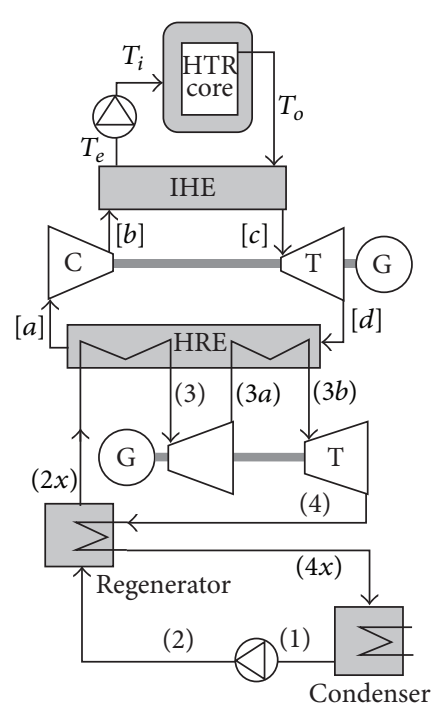

(a)

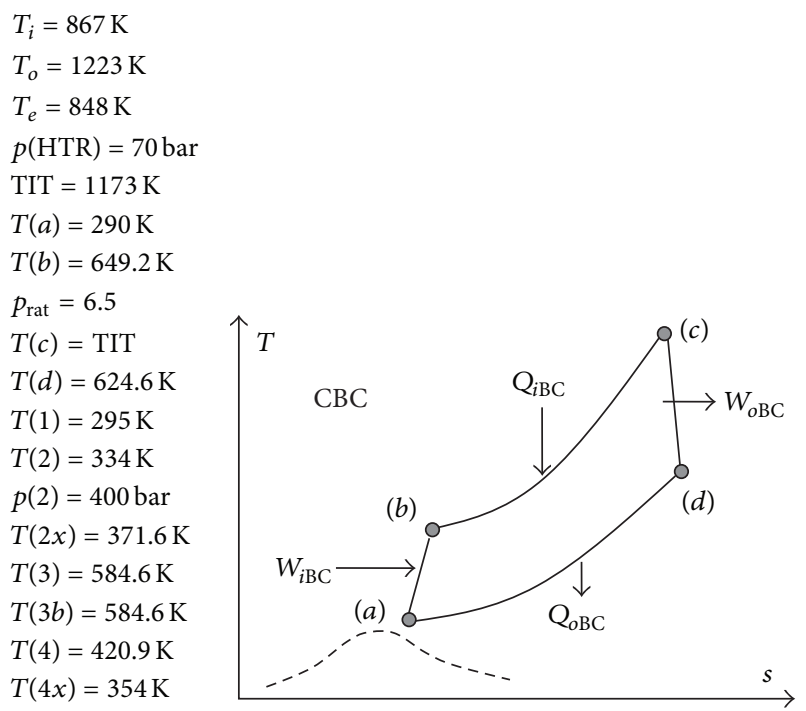

(b)

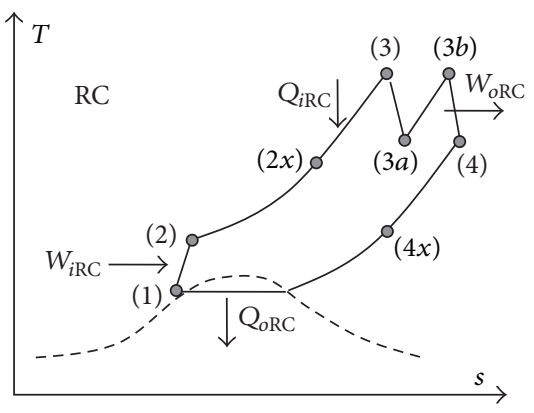

(c)

FIGURE 4: Diagram of the CC powered by helium cooled GT-MHR where the CBC operates with helium and the RC with carbon dioxide.

combined cycles are relevant. Conventional pressure ratios in CBC are currently lower than 45 , and depending mainly on the WF and the top cycle temperature, thermal efficiency can decrease even at very low pressure ratios.

The thermal efficiency, according the structure of the proposed CC shown in Figure 4, is defined as

$$
\eta_{\mathrm{CC}}=\frac{q_{i \mathrm{BC}}-r_{m} \cdot q_{o \mathrm{RC}}}{q_{i \mathrm{BC}}}
$$

where the ratio of heat flow rates is $r_{m}=q_{o \mathrm{BC}} / q_{i \mathrm{RC}}$.

The scheme shown in Figure 4 depicts a CBC powered by a helium cooled HTR. The top cycle is a CBC which works with helium as the WF where the efficiency is determined strongly by the temperature of the WF at the turbine inlet and the temperature at compressor suction (as low as technically possible).

The exhaust temperature from the turbine is such that an acceptable energy flow rate between both cycles ensures the bottoming cycle efficiency. This temperature is restricted to at least $40 \mathrm{~K}$ higher than the maximum temperature of the bottoming cycle WFs (ammonia, $700 \mathrm{~K}$, xenon $750 \mathrm{~K}$, ethane $675 \mathrm{~K}$, unlimited carbon dioxide and unlimited water).

The top and bottoming cycles consisting of a Brayton followed by RC are depicted in Figure 4. Optionally, depending on the WF, the RC can be more efficient with a single expansion. A regenerator is applied when necessary at the feed pump discharge. Low pressure turbine exhaust at quasicritical pressure (for carbon dioxide, xenon and ethane) towards the condenser implies delivering the WF at a temperature higher than its critical temperature. Consequently, in order to avoid unnecessary heat rejection, a fraction of the heat carried out with the WF to the condenser is recovered by means of a heat regenerator. As mentioned, such amount of heat is transferred to the WF after feed pump discharge.

In the scheme shown in Figure 4 , the heat rejected by the WF at the low pressure turbine exhaust side $\left(h_{4}-h_{4 x}\right)$ is recovered by the WF at feed pump discharge as $\left(h_{2 x}-h_{2}\right)$.

Although regeneration is a conventional means to increase the RC efficiency, in this case regeneration is placed between the low pressure turbine and the condenser, which is not typical in RCs. This contribution is relevant to efficiency enhancement when associated with the application of quasicritical condensation in combination with the proposed (organic or not) WFs.

The efficiency of the proposed quasicritical condensationbased RC is obtained as follows.

The supplied specific input heat flow for a unique turbine stage is defined as

$$
q_{i 1}=\left(h_{3}-h_{2 x}\right) .
$$


The supplied specific input heat flow for two turbine stages is defined as

$$
q_{i 2}=\left(h_{3}-h_{2 x}\right)+\left(h_{3 b}-h_{3 a}\right) .
$$

The specific output heat flow is defined as

$$
q_{o}=\left(h_{4 x}-h_{1}\right) .
$$

The specific network for a unique turbine stage is defined as

$$
w_{1}=\left(h_{3}-h_{4}\right)-\left(h_{2}-h_{1}\right) \text {. }
$$

The specific network for a two turbine stages is defined as

$$
w_{2}=\left(h_{3}-h_{3 a}\right)+\left(h_{3 b}-h_{4}\right)-\left(h_{2}-h_{1}\right) .
$$

The thermal cycle efficiency for a unique turbine stage is defined as

$$
\eta_{\mathrm{RC} 1}=\frac{w_{i}-w_{o}}{q_{i 1}} \approx \frac{w_{\mathrm{net}}}{q_{i 1}}=\frac{\left(h_{3}-h_{4}\right)-\left(h_{2}-h_{1}\right)}{\left(h_{3}-h_{2 x}\right)} .
$$

The thermal cycle efficiency for a two turbine stages is defined as

$$
\begin{aligned}
\eta_{\mathrm{RC} 2} & =\frac{w_{i}-w_{o}}{q_{i 2}} \approx \frac{w_{\text {net }}}{q_{i 2}} \\
& =\frac{\left(h_{3}-h_{3 a}\right)+\left(h_{3 b}-h_{4}\right)-\left(h_{2}-h_{1}\right)}{\left(h_{3}-h_{2 x}\right)+\left(h_{3 b}-h_{3 a}\right)} .
\end{aligned}
$$

According to the $T$-s diagram shown in Figure 4(c), in order to satisfy the 1 st and $2 \mathrm{~d}$ thermodynamic laws, the following conditions must be fulfilled.

1st principle:

$$
\left(h_{4}-h_{4 x}\right)=\left(h_{2 x}-h_{2}\right)
$$

2nd principle:

$$
\begin{array}{ll}
T_{4 x} \geq T_{2}, & T_{4} \geq T_{2 x} \\
T_{4} \geq T_{4 x}, & T_{2 x} \geq T_{2} .
\end{array}
$$

In trying to find the maximum achievable thermal efficiency of the cycle, the following considerations must be taken into account: according to expressions (9) and (10), maximum thermal cycle efficiency implies minimum $q_{i}$, which means maximum $h_{2 x}$ and minimum $h_{4 x}$. According to the expression (6) the cycle must satisfy the condition of $T_{4 x}>T_{2}$. Consequently, the minimum value for $h_{4 x}$ (the enthalpy at temperature $T_{4 x}$ ) is $h_{2}$, (the enthalpy at temperature $T_{2}$ ). Nevertheless, requirements for practical realisation demand a temperature difference $T_{4 x}-T_{2}$ of at least $20 \mathrm{~K}$ in order to permit an acceptable heat transfer flow. As consequence of such restriction, a compromise must exist between the mentioned temperature difference and the heat transfer flow which definitely affects the size of the plant.

The second law of thermodynamics introduces the concept of exergy. Exergy, also termed work availability or potential from the thermodynamic standpoint, is the maximum useful work obtainable from a system in a given state with respect to an environment, known as the reference environment. Unlike energy, which follows the first law of thermodynamics, exergy is destroyed as a result of the irreversibilities of the process due to the increase of entropy. Therefore, the exergy analysis allows the calculation of irreversibilities generated in the various components of the power plant.

The following equation is used to determine the flow exergy of a fluid under recognised conditions with negligible changes in kinetic and potential energies:

$$
e=h-h_{0}-T_{0}\left(s-s_{0}\right) \text {, }
$$

where $h_{0}$ and $s_{0}$ are the fluid properties in reference conditions $\left(T_{0}=298^{\circ} \mathrm{C}\right.$ and $p_{0}=1$ bar $)$ and $h$ and $s$ in the known conditions.

The rate of exergy destruction per unit of time is calculated by an exergy balance established in each component to be analysed and is given by the following:

$$
\dot{I}=\left(1-\frac{T_{0}}{T}\right) \dot{Q}-\dot{W}+\sum \dot{m}_{\text {in }} e_{\text {in }}-\sum \dot{m}_{\text {out }} e_{\text {out }} .
$$

Thus, the exergetic efficiency is defined by the following:

$$
\eta_{\mathrm{ex}}=\frac{\dot{W}_{\mathrm{net}}}{\dot{E}_{\mathrm{in}}},
$$

where $\dot{E}_{\text {in }}$ is the exergy input in the power plant and is calculated by

$$
\dot{E}_{\text {in }}=\dot{m}\left(h_{o}-h_{e}\right)
$$

\section{Case Studies: RC and CC Power Plants Powered by HTR'S}

The attainment of thermal efficiency enhancement is mainly due to the association of the following actions on the CC (topping $\mathrm{CBC}$ and bottoming $\mathrm{RC}$ or ORC).

For the topping cycle,

(i) the selected WF (helium) due to its inherent characteristics,

(ii) the highest achievable top temperature approaching a TIT of $1173 \mathrm{~K}$ which is lower than that of the power source in $50 \mathrm{~K}$,

(iii) the operating parameters (suitable pressure ratio, operating temperatures).

For the bottoming cycle,

(i) inherent regeneration, if applicable,

(ii) quasicritical condensation parameters, if applicable, which means rejecting the minimum possible amount of heat to the heat sink,

(iii) selection of a proper available organic and nonorganic WF (carbon dioxide, xenon, ethane, ammonia, or water). 
TABLE 4: Losses due to internal irreversibilities assumed for the case studies.

\begin{tabular}{|c|c|c|c|c|c|c|c|}
\hline & CBC-reg/He & $\mathrm{RC}-\mathrm{CO}_{2}$ & $\mathrm{He} / \mathrm{NH}_{3}$ (no reg) & $\mathrm{He} / \mathrm{CO}_{2}$ & $\mathrm{He} / \mathrm{C}_{2} \mathrm{H}_{6}$ (no reh) & $\mathrm{He} / \mathrm{H}_{2} \mathrm{O}$ (no reg) & $\mathrm{He} / \mathrm{Xe}$ (no reg) \\
\hline$p_{L}$ in HTR (\%) & 3 & 3 & 3 & 3 & 3 & 3 & 3 \\
\hline$p_{L}$ in $\mathrm{HE}(\%)$ & 2 & 2 & 2 & 2 & 2 & 2 & 3 \\
\hline$p_{L}$ in $\operatorname{HRE}(\%)$ & & & 2 & 2 & 2 & 2 & 3 \\
\hline$p_{L}$ regenerator $(\%)$ & 2 & 2 & & 2 & 2 & & \\
\hline$\eta \operatorname{IHE}(\%)$ & 97 & 92 & 92 & 92 & 92 & 92 & 92 \\
\hline$\eta \mathrm{HR}(\%)$ & & & 92 & 92 & 92 & 92 & 92 \\
\hline$\eta$ regenerator (\%) & 92 & 92 & & 90 & 92 & & \\
\hline$T_{L}$ HTR-IHE (K) & 50 & 80 & 50 & 50 & 50 & 50 & 50 \\
\hline $\operatorname{Reg}\left(T_{2 x}-T_{4}\right)(\mathrm{K})$ & 20 & 20 & & 20 & 20 & & \\
\hline$T_{L}$ in $\mathrm{BC} / \mathrm{RC}(\mathrm{K})$ & & - & 40 & 40 & 40 & 40 & 40 \\
\hline I $\eta \mathrm{BC}$ turbine (\%) & 94 & & 94 & 94 & 94 & 94 & 94 \\
\hline $\mathrm{I} \eta \mathrm{BC}$ compressor $(\%)$ & 88 & & 88 & 88 & 88 & 88 & 88 \\
\hline I $\eta$ RC pump (\%) & & 90 & 90 & 90 & 90 & 90 & 90 \\
\hline I $\eta \mathrm{RC}$ turbine (\%) & & 92 & 92 & 92 & 92 & 92 & 92 \\
\hline
\end{tabular}

Ferreiro Garcia et al. [16] present a research work dealing with very high temperature reactors which operate with helium as cooling fluid for the primary loop. This work shows that cost effective performance enhancement can be achieved under safe operating conditions by means of alternative thermal cycles to the conventional steam Rankine and combined cycles. The proposed improvements required the implementation of some RC structures operating with carbon dioxide condensed at quasicritical conditions, combined with RC coupled in series where carbon dioxide or water are used in order to achieve cooling capacity. Continuing with this research line, some optimised power plant structures exhibiting interesting characteristics are still possible. Thus, the analysis of the following optional cycle structures is proposed:

(i) a stand alone $\mathrm{CBC}$ operating with helium as $\mathrm{WF}$,

(ii) a stand alone $\mathrm{RC}$ operating with $\mathrm{CO}_{2}$, and

(iii) a combined cycle (BC-RC) operating with helium for the topping cycle and carbon dioxide, xenon, ethane, ammonia or water for the bottoming cycle.

All the information required to evaluate the thermodynamic properties of the WFs, as well as the valid criteria for choosing them as part of the research work, has been obtained from [17] associated with the Engineering Equation Solver [18] used in these case study solving tasks. The methodology followed was the programming on EES of all equations required to establish energy and exergy balances at each component of the plant, identifying from the start which variables are considered to be baseline data, and which variables were to be calculated or optimised, while complying with the model from a mathematical and physical perspective, that is, an equal number of equations as variables to calculate, while fulfilling the first and second laws of thermodynamics.

To validate the model, a triple analysis was carried out seeking

(i) coherence between the two methods of calculating condenser heat, that is, the heat rejected by the condenser calculated by applying the energy balance to the whole plant, must be equal to that calculated by the energy balance in the condenser alone,

(ii) all irreversibilities must be positive or equal and all entropies generated must be positive,

(iii) the total irreversibility calculated by exergy balance over the entire cycle (variation of universe entropy) is equal to the value calculated as the total irreversibilities of all components.

Losses due to internal irreversibilities have been taken into account in the considered case studies. Thus, in Table 4, a list of the assumed losses in the analysis is shown.

4.1. Stand Alone Regenerative Brayton Driven by an HTR with an Intermediate Heat Exchanger. The plant structure based on a CC is shown in Figure 4, which operates with a TIT of $1173 \mathrm{~K}$ and assigned isentropic efficiencies according to Table 4, including its inherent internal irreversibilities.

The topping $\mathrm{CBC}$ is studied for helium where several pressure ratios are considered so that once a performance criteria based on the maximum thermal efficiency has been assumed, the availability of the analysed results permits us to choose the most convenient operating conditions according to the information provided with Figure 5. In this way, Table 5 shows the relevant state points of the regenerative $\mathrm{CBC}$, for which an optimal pressure ratio of 2.37 renders the maximum thermal efficiency, as depicted in Figure 5.

\subsection{Stand Alone RC Based HTR Power Plant with Intermediate} Heat Exchange. The power plant structure based on a stand alone RC is depicted in Figure 3. The assumed isentropic efficiencies are shown in Table 4. The double expansion RC state points for $\mathrm{CO}_{2}$ as the WF are depicted in Table 6 .

The optimal reheating pressure is the value of the reheating pressure that corresponds to the maximum thermal efficiency. According to Figure 6, the optimum reheating 


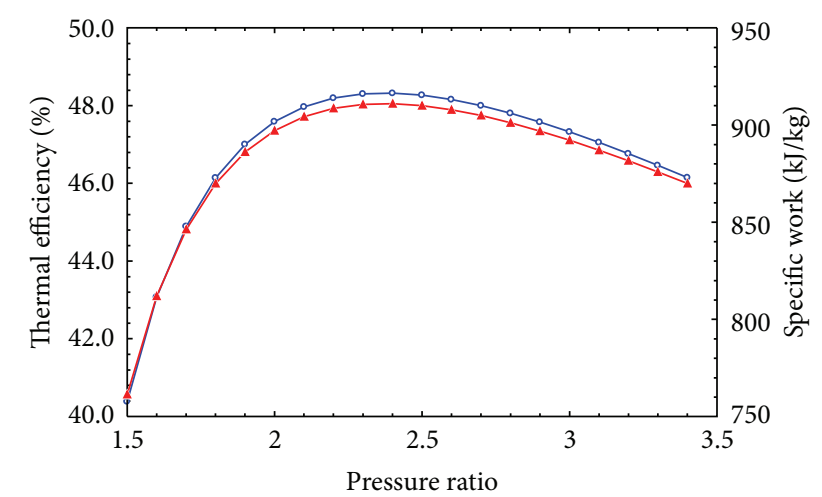

Figure 5: Thermal efficiency and specific work as function of the pressure ratio for the regenerative $\mathrm{CBC}$ operating with helium as WF and TIT $1173 \mathrm{~K}$.

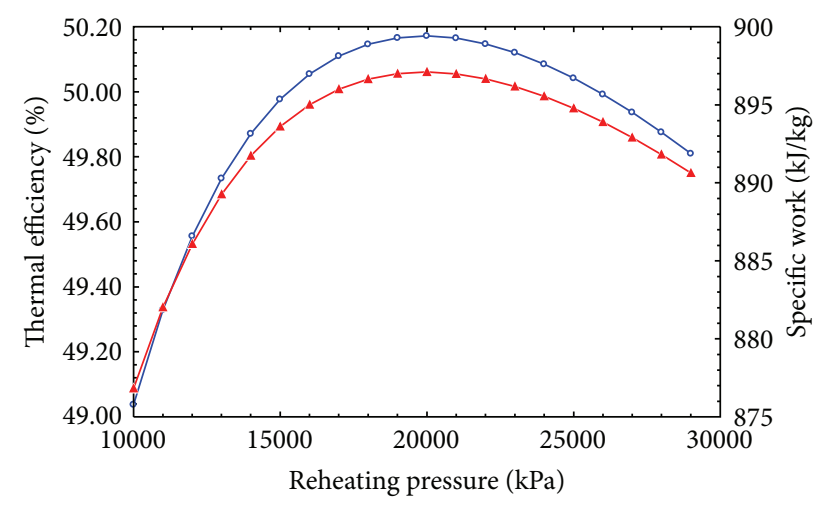

Figure 6: The stand alone RC thermal efficiency and specific power as function reheating pressure operating with carbon dioxide, computed with data from Table 4.

TABLE 5: The CBC with helium as WF operating with a TIT of $1173 \mathrm{~K}$ and pressure ratio of 2.37 .

\begin{tabular}{lcccc}
\hline Point & $a$ & $b$ & $c$ & $d$ \\
\hline$T(\mathrm{~K})$ & 290 & 426 & 1173 & 876.2 \\
$p(\mathrm{kPa})$ & 100 & 237.2 & 227.8 & 104 \\
$h(\mathrm{~kJ} / \mathrm{kg})$ & -42.32 & 663.92 & 4543.59 & 876.28 \\
$v\left(\mathrm{~m}^{3} / \mathrm{kg}\right)$ & 6.023 & 3.73 & 10.69 & 17.57 \\
\hline
\end{tabular}

pressure corresponds to $19800 \mathrm{kPa}$, rendering a maximum thermal efficiency of $50.17 \%$ and maximum specific power of $897.1 \mathrm{~kJ} / \mathrm{kg}$.

4.3. Analysis of the Combined Cycle Based HTR Power Plant. Table 7 presents the state points of both the topping BC with helium and the bottoming RC operating with carbon dioxide, xenon, ethane, ammonia and water as WFs. Although the RC analysis has been performed for single and double expansion turbine cycles, only the results of two-turbine based cycles are presented since thermal efficiency for a single turbine based cycle is significantly lower.

The CC results computed with data from Table 7, which operates optionally with carbon dioxide, xenon, ethane,

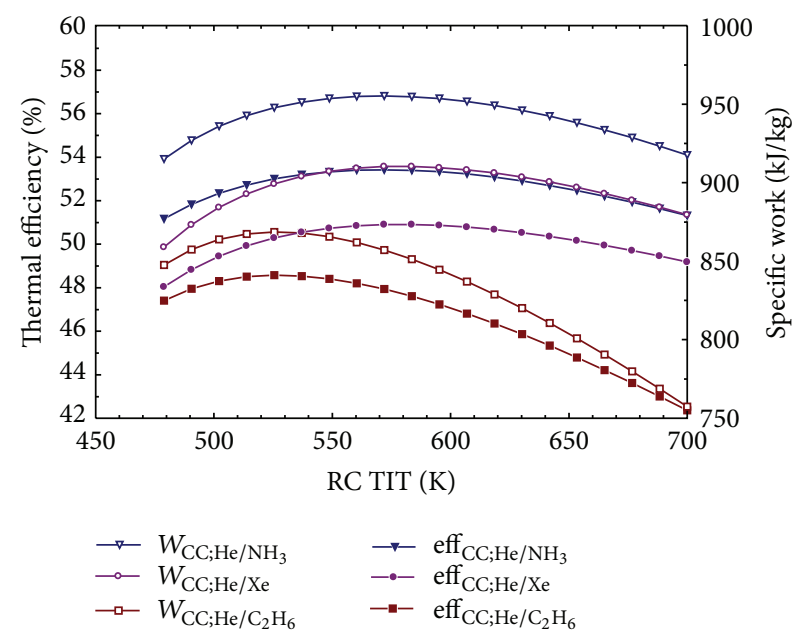

FIGURE 7: Thermal efficiency and specific power as function of the bottoming RC TIT for the He- $\mathrm{NH}_{3}, \mathrm{He}-\mathrm{Xe}$ and $\mathrm{He}-\mathrm{C}_{2} \mathrm{H}_{6}$ as WFs.

ammonia or water as WFs are depicted in Figure 7, respectively. Thus the thermal efficiency, the specific power, the ratio of the coolant mass flow rate $(\mathrm{He})$ to the specific power, the TIT (K), the ratio of the WF mass flow rate to the reactor coolant mass flow rate for the $\mathrm{BC}$ and RCs, as well as the $\mathrm{BC}$ pressure ratio as function of the bottoming RC TIT are depicted.

The thermal efficiency and specific power as function of the bottoming RC TIT is depicted in Figure 7 for the $\mathrm{He}-\mathrm{NH}_{3}$, $\mathrm{He}-\mathrm{Xe}$, and $\mathrm{He}-\mathrm{C}_{2} \mathrm{H}_{6}$ as WFs.

Table 8 shows the main results of the studied cases, highlighting for every cycle structure the thermal efficiency, the specific power, the ratio of the coolant $(\mathrm{He})$ mass flow rate to the specific power, the topping BC TIT $(\mathrm{K})$, the bottoming RC TIT (K), the ratio of the WF mass flow rate to the reactor coolant mass flow rate for the $\mathrm{BC}$ and RCs, as well as the Brayton pressure ratio.

\section{Discussion of Results and Conclusions}

The results of an HTR based power plant implemented optionally with a stand alone BC operating with helium, a stand alone $\mathrm{RC}$ operating with carbon dioxide or a chosen $\mathrm{CC}$ operating alternatively with $\mathrm{He}-\mathrm{CO}_{2}, \mathrm{He}-\mathrm{Xe}, \mathrm{He}-\mathrm{C}_{2} \mathrm{H}_{6}$, $\mathrm{He}-\mathrm{NH}_{3}$ or $\mathrm{He}-\mathrm{H}_{2} \mathrm{O}$ as WFs, designed with an IHE (heliumWF) are under the scope of the discussion of the analysis results. The IHE isolates the HTR based nuclear reactor from the heat application process, allowing the system to be built to nonnuclear standards. The IHE also establishes additional physical barriers between the reactor and the process heat loop. Additional barriers will help reduce contamination from activated radionuclides such as cobalt, which may be abundant in some high-temperature alloys. However, there are still several issues to be resolved before an adequate IHE can be efficiently designed. Due to the low heat transfer properties of carbon dioxide, the IHE will require an extremely large surface area for satisfying the required heat transfer rate.

The HTR based power plant implemented with a stand alone regenerative $\mathrm{CBC}$ operating with helium renders 
TABLE 6: The double expansion RC state points for $\mathrm{CO}_{2}$ as WF.

\begin{tabular}{lcccccccc}
\hline Point & 1 & 2 & 3 & $3 a$ & $3 b$ & 4 & $4 x$ & $2 x$ \\
\hline$T(\mathrm{~K})$ & 295 & 334.6 & 1143 & 1038 & 1143 & 354.6 & 354.6 & 774.2 \\
$p(\mathrm{kPa})$ & 5982 & 41616 & 40000 & 20196 & 19800 & 6102 & 5982 & 40800 \\
$h(\mathrm{~kJ} / \mathrm{kg})$ & -244.5 & -197.3 & 933.6 & 796.8 & 934.3 & 713.8 & 6.939 & 453 \\
$v \cdot 10^{-3}\left(\mathrm{~m}^{3} / \mathrm{kg}\right)$ & 1.328 & 1.125 & 5.949 & 10.09 & 11.36 & 30.27 & 9.294 & 3.882 \\
\hline
\end{tabular}

TABLE 7: The CC state points for the CBC with helium as WF and carbon dioxide, xenon, ethane, ammonia and water as WF for the RC.

\begin{tabular}{|c|c|c|c|c|c|c|c|c|c|c|c|c|}
\hline Point & $a$ & $b$ & $c$ & $d$ & 1 & 2 & 3 & $3 a$ & $3 b$ & 4 & $4 x$ & $2 x$ \\
\hline \multicolumn{13}{|c|}{$\mathrm{He}-\mathrm{CO}_{2}$} \\
\hline$T(\mathrm{~K})$ & 290 & 691.8 & 1173 & 575.2 & 295 & 335.9 & 535.2 & 510 & 535.2 & 384.4 & 355.9 & 352.1 \\
\hline$p(\mathrm{kPa})$ & 100 & 733.3 & 718.6 & 102 & 5982 & 41616 & 40000 & 31140 & 30529 & 6102 & 5982 & 40800 \\
\hline$v \cdot 10^{3}\left(\mathrm{~m}^{3} / \mathrm{kg}\right)$ & 6023 & 196 & 339 & 1171 & 1.328 & 1.125 & 2.458 & 2.839 & 3.121 & 10.34 & 9.249 & 1.203 \\
\hline \multicolumn{13}{|c|}{ He-Xe (no regeneration) } \\
\hline$T(\mathrm{~K})$ & 290 & 632.2 & 1173 & 620 & 282 & 363.8 & 580 & 495.4 & 580 & 333.9 & & \\
\hline$p(\mathrm{kPa})$ & 100 & 593 & 581.1 & 102 & 4985 & 40800 & 40000 & 24480 & 24000 & 4985 & & \\
\hline$v \cdot 10^{3}\left(\mathrm{~m}^{3} / \mathrm{kg}\right)$ & 6023 & 2214 & 4192 & 1263 & 0.588 & 0.499 & 0.929 & 1.121 & 1.457 & 3.347 & & \\
\hline \multicolumn{13}{|c|}{$\mathrm{He}-\mathrm{C}_{2} \mathrm{H}_{6}$ (no reheating) } \\
\hline$T(\mathrm{~K})$ & 290 & 706.9 & 1173 & 565 & 295 & 342.5 & 525 & & & 382.8 & 362.5 & 385.3 \\
\hline$p(\mathrm{kPa})$ & 100 & 771.8 & 756.4 & 102 & 3918 & 41616 & 40000 & & & 3997 & 3918 & 40800 \\
\hline$v \cdot 10^{3}\left(\mathrm{~m}^{3} / \mathrm{kg}\right)$ & 6023 & 1902 & 3221 & 11510 & 3.021 & 2.37 & 3.841 & & & 22.77 & 21.22 & 2.473 \\
\hline \multicolumn{13}{|c|}{$\mathrm{He}-\mathrm{NH}_{3}$ (no regeneration) } \\
\hline$T(\mathrm{~K})$ & 290 & 597.5 & 1173 & 650 & 295 & 305.9 & 570 & 472 & 570 & 318.6 & & \\
\hline$p(\mathrm{kPa})$ & 100 & 519.2 & 508.9 & 102 & 909.6 & 41208 & 40000 & 15810 & 15500 & 909.6 & & \\
\hline$v \cdot 10^{3}\left(\mathrm{~m}^{3} / \mathrm{kg}\right)$ & 6023 & 2390 & 4788 & 13240 & 1.646 & 1.601 & 5.015 & 9.587 & 15.42 & 157.7 & & \\
\hline \multicolumn{13}{|c|}{$\mathrm{He}-\mathrm{H}_{2} \mathrm{O}$ (no regeneration) } \\
\hline$T(\mathrm{~K})$ & 290 & 459.7 & 1173 & 810 & 295 & 296.6 & 770 & 598.2 & 770 & 295 & & \\
\hline$p(\mathrm{kPa})$ & 100 & 282.3 & 276.7 & 102 & 2.621 & 35012 & 34325 & 10751 & 10540 & 2.621 & & \\
\hline$v \cdot 10^{3}\left(\mathrm{~m}^{3} / \mathrm{kg}\right)$ & 6023 & 3381 & 8805 & 16490 & 1.002 & 0.987 & 7.028 & 17.64 & 30.77 & 41380 & & \\
\hline
\end{tabular}

TABLE 8: Main results achieved from the case study for comparison purposes.

\begin{tabular}{|c|c|c|c|c|c|c|c|}
\hline & \multirow{2}{*}{$\mathrm{CBC}(\mathrm{He})$} & \multirow{2}{*}{$\mathrm{RC}\left(\mathrm{CO}_{2}\right)$} & \multicolumn{5}{|c|}{ Combined cycle options } \\
\hline & & & $\mathrm{He}-\mathrm{CO}_{2}$ & $\mathrm{He}-\mathrm{Xe}$ & $\mathrm{He}-\mathrm{C}_{2} \mathrm{H}_{6}$ & $\mathrm{He}-\mathrm{NH}_{3}$ & $\mathrm{He}-\mathrm{H}_{2} \mathrm{O}$ \\
\hline$\eta(\%)$ & 45.79 & 50.17 & 49.51 & 50.91 & 48.58 & 53.51 & 53.63 \\
\hline$\eta_{\text {ex }}(\%)$ & 62.07 & 64.51 & 63.66 & 65.46 & 62.46 & 68.79 & 53.63 \\
\hline$w(\mathrm{~kJ} / \mathrm{kg})$ & 863.3 & 897.1 & 885.4 & 910.4 & 868.6 & 956.7 & 959.0 \\
\hline Ratio WF/w (kg/MW) & 1.158 & 1.115 & 1.129 & 1.098 & 1.151 & 1.045 & 1.043 \\
\hline TIT (K) & 1173 & 1143 & 535.2 & 580 & 525 & 570 & 770 \\
\hline$\dot{m}_{\mathrm{CBC}}$ & 1.034 & - & 0.714 & 0.637 & 0.739 & 0.652 & 0.483 \\
\hline$\dot{m}_{\mathrm{RC}}$ & - & 2.893 & 1.840 & 7.717 & 1.135 & 0.458 & 0.316 \\
\hline$p_{\text {rat }}$ & 2.37 & - & 7.33 & 5.93 & 7.72 & 6.21 & 2.82 \\
\hline$\dot{E}_{\text {in }}$ & 1390.7 & 1390.7 & 1390.7 & 1390.7 & 1390.7 & 1390.7 & 1390.7 \\
\hline$\sum \dot{I}_{\text {component }}$ & 368.7 & 432.2 & 328.3 & 310.5 & 325.4 & 273.8 & 202.3 \\
\hline
\end{tabular}

acceptable thermal efficiency and specific power $(45.79 \%$ and $863.3 \mathrm{~kW} / \mathrm{kg}$ ). Taking into consideration the structural simplicity associated with its implementation and exploitation costs, it can be deduced that this installation exhibits an interesting characteristic based on its effective cost, despite rendering a lower thermal efficiency.

With regard to the $\mathrm{CC}$, the topping Brayton and the bottoming Rankine parameters are adjusted so that the maximum feasible thermal efficiency is achieved. In this regard the low thermal efficiency of the CC helium-ethane (48.58\%) is worth noting. Accordingly, the specific power is also lower than in the rest of the CC options.

The option based in the $\mathrm{He}-\mathrm{CO}_{2} \mathrm{CC}$ renders lower thermal efficiency than the stand alone Rankine with $\mathrm{CO}_{2}$, which makes the $\mathrm{CC}$ based on $\mathrm{He}-\mathrm{CO}_{2}$ unfeasible with respect to the stand alone $\mathrm{RC}$ with $\mathrm{CO}_{2}$. 
TABle 9: The optimal parameters of the CC $\mathrm{He}-\mathrm{H}_{2} \mathrm{O}$.

\begin{tabular}{|c|c|c|c|c|c|c|c|c|c|}
\hline & $x_{4}$ & $v_{4}\left(\mathrm{~m}^{3} / \mathrm{kg}\right)$ & $T_{3}=T_{3 b}(\mathrm{~K})$ & $p_{3}(\mathrm{kPa})$ & $P_{3 b}(\mathrm{kPa})$ & $p_{\text {rat }}$ & $\eta_{\mathrm{cc}}$ & $\eta_{\text {ex }}(\%)$ & $w(\mathrm{~kJ} / \mathrm{kg})$ \\
\hline$\overline{\mathrm{CC} \_\mathrm{He} / \mathrm{H}_{2} \mathrm{O}}$ & 0.798 & 41.38 & 770 & 34325 & 10540 & 2.823 & 53.63 & 68.96 & 959 \\
\hline
\end{tabular}

However, while options based on $\mathrm{He}-\mathrm{Xe}, \mathrm{He}-\mathrm{C}_{2} \mathrm{H}_{6}$ provide acceptable intermediate values, the $\mathrm{He}-\mathrm{NH}_{3}$ and $\mathrm{He}$ $\mathrm{H}_{2} \mathrm{O}$ options stand favorably against the rest of those analysed options. Thus, the option of $\mathrm{He}-\mathrm{NH}_{3}$, and $\mathrm{He}-\mathrm{H}_{2} \mathrm{O}$ for the $\mathrm{CC}$ renders the maximum thermal efficiency among the studied options with more than $53 \%$.

In an attempt to optimise the bottoming $\mathrm{RC}$ operating parameters taking the maximum thermal efficiency of the Brayton-Rankine as optimisation criterion, some constraints limit our degree of freedom concerning the steam parameters. Thus, the specific volume and the steam dryness fraction $(x)$ at point (4), significantly limit the feasible operating range of steam parameters. In this regard, the values achieved at point (4), approach a specific volume of $40 \mathrm{~m}^{3} / \mathrm{kg}$ with a steam dryness fraction of 0.8 , as shown in Table 9 . In the same way, the steam properties at point $(3 a)$ must consider a slightly overheated steam to avoid saturation, preventing deterioration of the turbine safety operating conditions.

According to these constraints, the parameters of Table 9 have been achieved, satisfying the criterion of maximum thermal efficiency for the CC $\mathrm{He}-\mathrm{H}_{2} \mathrm{O}$.

These results, however, shown in Table 8 propose a significant increase in efficiency with respect to conventional HTR based power plants with stand alone BC. These results show the advantages of the CC in terms of thermal efficiency compared to the $\mathrm{BC}$, although the costs of installation and maintenance are significantly higher.

5.1. Conclusions. A research work focused on the performance analysis of conventional CC operating with helium at the topping $\mathrm{BC}$ and carbon dioxide, xenon, ethane, ammonia or water for the bottoming RC, powered by an HTR has been performed. The study aims to determine the working fluid and the structure of the thermal cycle which renders maximum performance under acceptable hence specific power.

The part of the study based on the implementation of some bottoming RC structures operating with carbon dioxide, xenon, or ethane condensed at quasicritical conditions, were aimed at providing high efficiency while maintaining the required cooling capacity of the reactor. In the same way, the implementation of some bottoming RC structures operating with water and ammonia condensed at ambient temperatures demonstrated good coupling characteristics and acceptable thermal efficiency.

The ultrasupercritical RC operating with carbon dioxide condensed at quasicritical conditions renders a thermal efficiency higher than that of the conventional helium cooled HTR based power plants.

The CC operating with helium under a pressure ratio approaching 2.5-3.5, coupled with a bottoming RC operating with carbon dioxide, xenon, ethane, ammonia, or water, also returns higher efficiency than the conventional BC (45.79\%).

From the information provided by Figure 7 regarding bottoming $\mathrm{RC}$, it follows that the temperature of the heat sink is limited by one of either ambient temperature or quasicritical condensation temperature. Furthermore, the CC feasibility depends significantly on the value of the top cycle TIT, meaning that higher top temperatures imply that greater pressure ratios are possible and consequently greater thermal efficiency and specific power. Nevertheless, a limit in pressure ratio exists, which is determined by the gas turbine exhaust temperature. Such value should be greater than the RC TIT of at least $50 \mathrm{~K}$. Since the pressure ratio is limited by the exhaust gas turbine temperature demand, thermal efficiency and specific power are also limited.

The viable way to decrease the effect of such limitations demands a strong effort in achieving

(i) combined cycle TIT as high as possible,

(ii) HRE input temperature (or gas turbine exhaust) at a temperature close to the maximum temperature withstood by the WFs of the RC plus at least $20 \mathrm{~K}$ to facilitate heat transfer from the Brayton heat sink to the Rankine heat source at the required heat flow rate,

(iii) HRE output temperature (or gas compressor input) at the minimum temperature close to the temperature achieved by the WFs of the RC after the regenerator, plus at least $20 \mathrm{~K}$ to facilitate the required heat flow rate.

As consequence of the mentioned limitations, the pressure ratio is imposed as well as the thermal efficiency and specific power. Nevertheless, the low specific volume of the WFs applicable to the $\mathrm{RC}$ in comparison with water, together with the condensation conditions, which are at a significantly higher pressure than the atmospheric pressure, means that the weight and volume of the condenser and $\mathrm{RC}$ turbines are significantly reduced. As consequence, the application of the proposed techniques aimed at performance enhancement by increasing thermal efficiency requires the design of high pressure condensers, regenerators, and back-pressure turbines as well as higher temperature gas turbines.

\section{Nomenclature}

$C_{p}:$ Specific heat $(\mathrm{kJ} / \mathrm{kg}-\mathrm{K})$

$\dot{E}_{\text {in }}$ : Exergy input in the power plant $(\mathrm{kW})$

$h: \quad$ Specific enthalpy $(\mathrm{kJ} / \mathrm{kg})$

$I_{\eta}: \quad$ isentropic efficiency

$\dot{I}: \quad$ Irreversibility $(\mathrm{kW})$

$\dot{m}$ : HTR coolant mass flow rate $(\mathrm{kg} / \mathrm{s})$

$p$ : Pressure (bar)

$p_{L}$ : Pressure losses (internal irreversibilities)

$p_{\text {rat }}$ : Pressure ratio of the CC

$p_{\text {reh }}:$ Intermediate reheating pressure (bar)

q: $\quad$ Specific heat $(\mathrm{kJ} / \mathrm{kg})$

$\dot{Q}: \quad$ Heat transfer rate $(\mathrm{kW})$ 


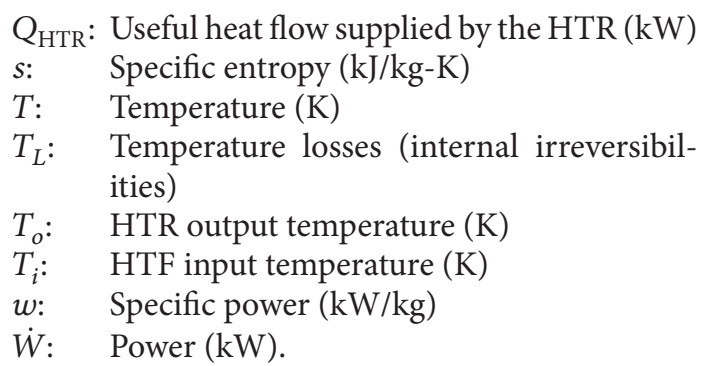

\section{Greek Letters}

$\eta$ : Thermal efficiency

$\eta_{R}$ : Thermal efficiency of the RC

$\eta_{B}$ : Thermal efficiency of the CBC

$\eta_{\mathrm{CC}}$ : Thermal efficiency of the CC.

\section{Acronyms}

BC: $\quad$ Brayton cycle

CBC: $\quad$ Closed Brayton cycle

CC: $\quad$ Combine cycle

DHR: Decay heat removal

GT-MHR: Gas turbine modular helium reactor

HE: $\quad$ Heat exchanger

HTR: High temperature reactor

HRE: Heat recovery exchanger

IHE: Intermediate heat exchanger

ORC: $\quad$ Organic Rankine cycle

PCS: $\quad$ Power conversion system

RC: $\quad$ Rankine cycle

SFR: $\quad$ Sodium cooled fast reactors

TIT: $\quad$ Turbine input temperature

WF: $\quad$ Working fluid.

\section{Conflict of Interests}

The authors declare that there is no conflict of interests regarding the publication of this paper.

\section{References}

[1] J. E. Kelly, "Generation IV international forum: a decade of progress through international cooperation," Progress in Nuclear Energy, vol. 77, pp. 240-245, 2014.

[2] Y. Ahn and J. I. Lee, "Study of various Brayton cycle designs for small modular sodium-cooled fast reactor," Nuclear Engineering and Design, vol. 276, pp. 128-141, 2014.

[3] Y. Xu, S. Hu, F. Li, and S. Yu, "High temperature reactor development in China," Progress in Nuclear Energy, vol. 47, no. 1-4, pp. 260-270, 2005.

[4] N. Chrysanthopoulou, P. Savva, M. Varvayanni, and N. Catsaros, "Compilation of existing neutron screen technology," Science and Technology of Nuclear Installations, vol. 2014, Article ID 395795, 23 pages, 2014.

[5] M. K. Rowinski, T. J. White, and J. Zhao, "Small and medium sized reactors (SMR): a review of technology," Renewable and Sustainable Energy Reviews, vol. 44, pp. 643-656, 2015.
[6] M. A. Fütterer, L. Fu, C. Sink et al., "Status of the very high temperature reactor system," Progress in Nuclear Energy, vol. 77, pp. 266-281, 2014.

[7] G. Black, M. A. T. Black, D. Solan, and D. Shropshire, "Carbon free energy development and the role of small modular reactors: a review and decision framework for deployment in developing countries," Renewable and Sustainable Energy Reviews, vol. 43, pp. 83-94, 2015.

[8] T. Takizuka, "Reactor technology development under the HTTR Project," Progress in Nuclear Energy, vol. 47, no. 1-4, pp. 283-291, 2005.

[9] F. J. Mackay, G. E. Apostolakis, and P. Hejzlar, "Incorporating reliability analysis into the design of passive cooling systems with an application to a gas-cooled reactor," Nuclear Engineering and Design, vol. 238, no. 1, pp. 217-228, 2008.

[10] M. S. El-Genk and J.-M. Tournier, "Noble gas binary mixtures for gas-cooled reactor power plants," Nuclear Engineering and Design, vol. 238, no. 6, pp. 1353-1372, 2008.

[11] H. Zhao and P. F. Peterson, "Multiple reheat helium Brayton cycles for sodium cooled fast reactors," Nuclear Engineering and Design, vol. 238, no. 7, pp. 1535-1546, 2008.

[12] W. Shuyan, L. Xiang, L. Huilin, J. Bouillard, S. Qiaoqun, and W. Shuai, "Simulations of flow behavior of fuel particles in a conceptual helium-cooled spout fluidized bed nuclear reactor," Nuclear Engineering and Design, vol. 239, no. 1, pp. 106-115, 2009.

[13] A. Epiney, K. Mikityuk, and R. Chawla, "Heavy-gas injection in the Generation IV gas-cooled fast reactor for improved decay heat removal under depressurized conditions," Nuclear Engineering and Design, vol. 240, no. 10, pp. 3115-3125, 2010.

[14] K. Ohashi, F. Okamoto, and H. Hayakawa, "Modular high temperature reactor (Modular HTR) contributing the global environment protection," Progress in Nuclear Energy, vol. 37, no. 1-4, pp. 307-312, 2000.

[15] R. F. Garcia, J. C. Carril, A. D. Catoira, and J. R. Gomez, "Efficiency enhancement of GT-MHRs applied on ship propulsion plants," Nuclear Engineering and Design, vol. 250, pp. 326-333, 2012.

[16] R. Ferreiro Garcia, M. R. Gomez, J. C. Carril, and J. R. Gomez, "VHTR-based power plants' performance enhancement using Rankine cycles," Progress in Nuclear Energy, vol. 71, pp. 206-215, 2014.

[17] E. W. Lemmon, M. L. Huber, and M. O. McLinden, NIST Reference Fluid Thermodynamic and Transport PropertiesREFPROP Version 8.0, User's Guide, NIST, Boulder, Colo, USA, 2007.

[18] S. A. Klein, Engineering equation solver (EES), Academic Professional V9.172, 2012. 


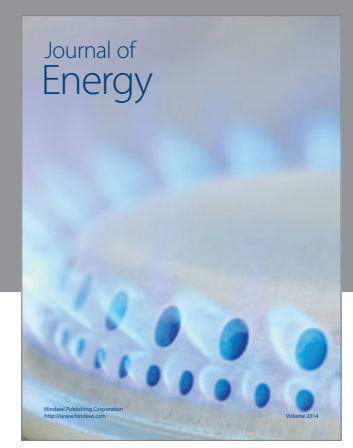

Journal of

Industrial Engineering
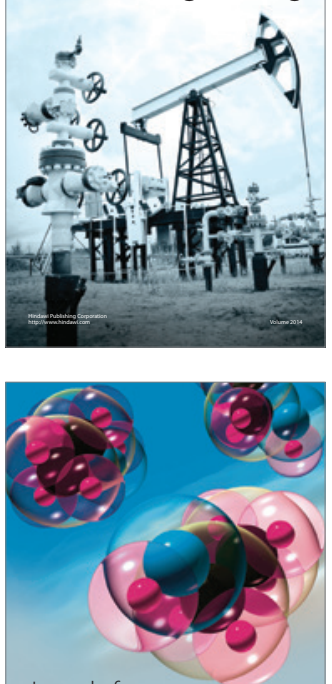

Fuels
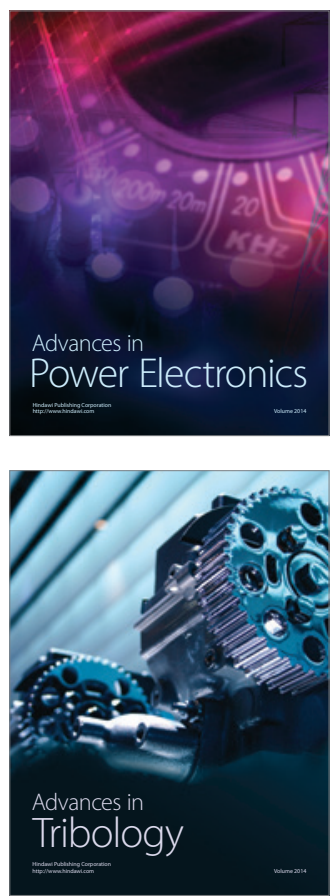

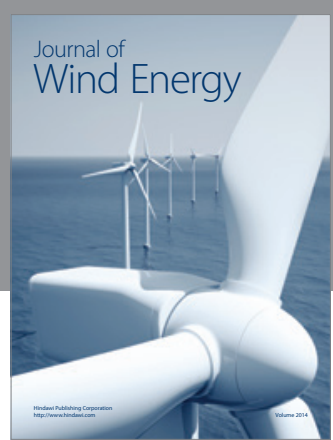

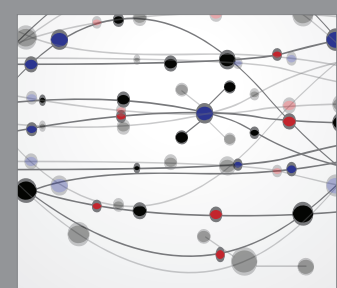

The Scientific World Journal

Submit your manuscripts at http://www.hindawi.com

Journal of

Structures
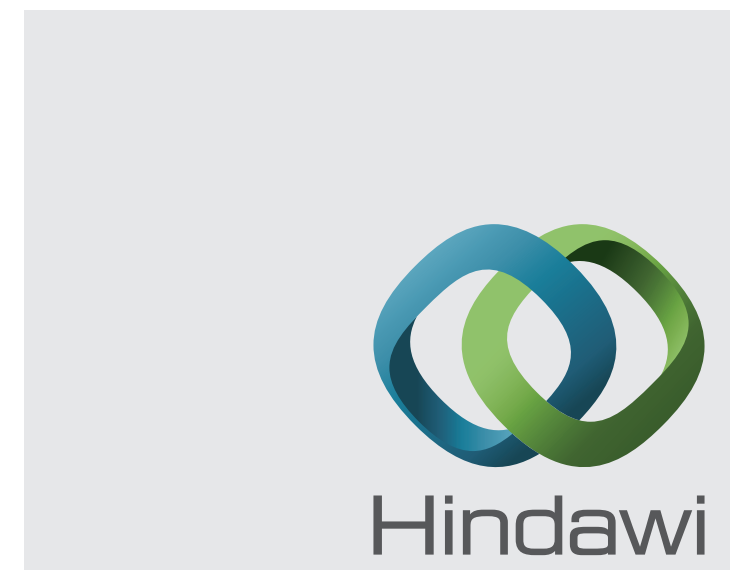

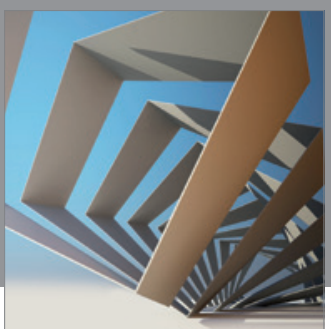

Rotating

Machinery
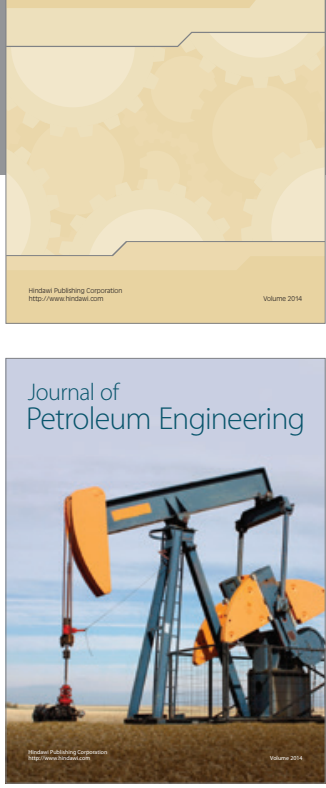

Journal of

Solar Energy
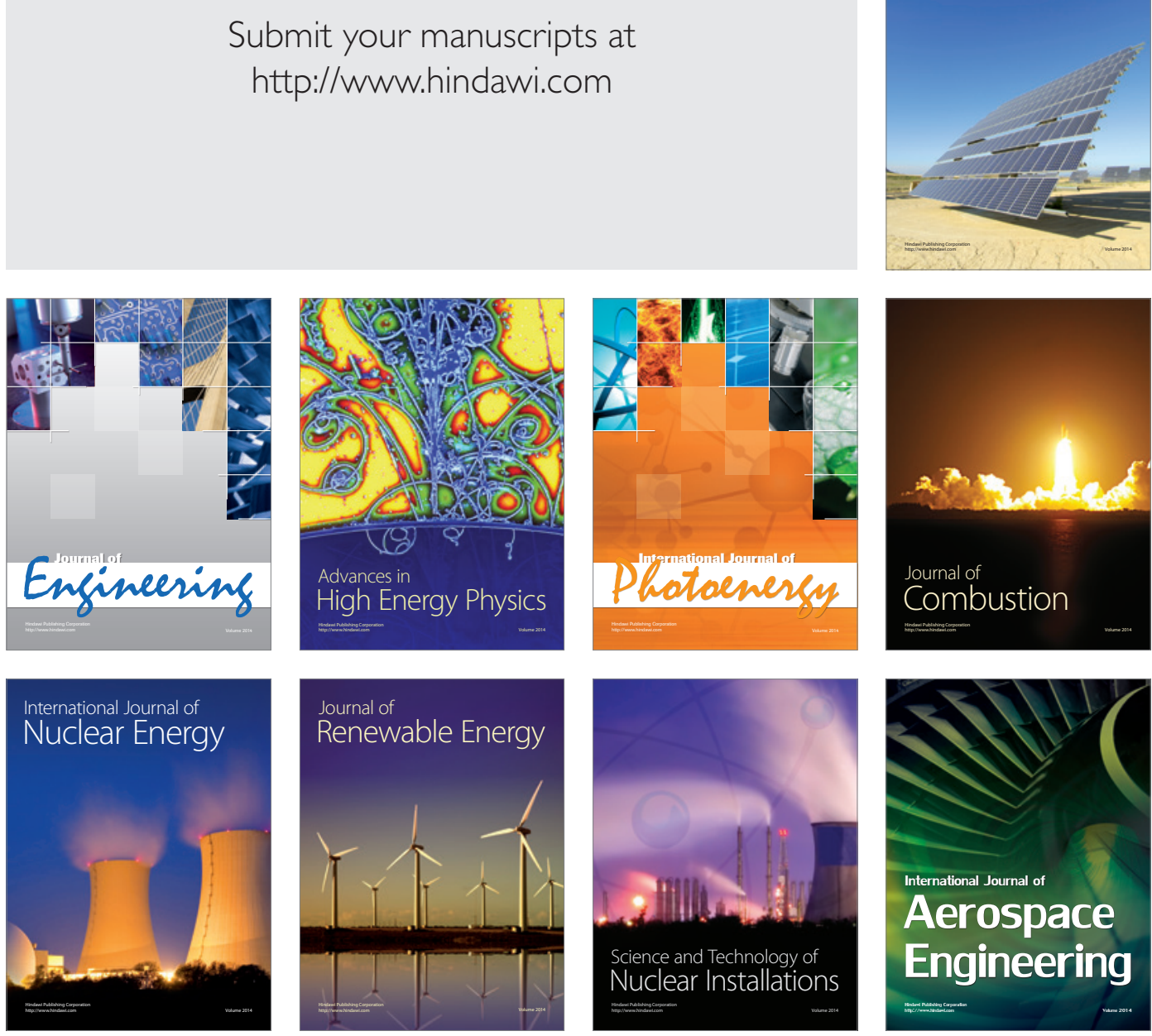